\title{
Electrochemical Migration on Electronic Chip Resistors in Chloride Environments
}

\author{
Minzari, Daniel; Jellesen, Morten Stendahl; Møller, Per; Wahlberg, Pia; Ambat, Rajan
}

Published in:

I E E E Transactions on Device and Materials Reliability

Link to article, DOI:

10.1109/TDMR.2009.2022631

Publication date:

2009

Document Version

Publisher's PDF, also known as Version of record

Link back to DTU Orbit

Citation (APA):

Minzari, D., Jellesen, M. S., Møller, P., Wahlberg, P., \& Ambat, R. (2009). Electrochemical Migration on Electronic Chip Resistors in Chloride Environments. I E E E Transactions on Device and Materials Reliability, 9(3), 392-402. https://doi.org/10.1109/TDMR.2009.2022631

\section{General rights}

Copyright and moral rights for the publications made accessible in the public portal are retained by the authors and/or other copyright owners and it is a condition of accessing publications that users recognise and abide by the legal requirements associated with these rights.

- Users may download and print one copy of any publication from the public portal for the purpose of private study or research.

- You may not further distribute the material or use it for any profit-making activity or commercial gain

- You may freely distribute the URL identifying the publication in the public portal 


\title{
Electrochemical Migration on Electronic Chip Resistors in Chloride Environments
}

\author{
Daniel Minzari, Morten S. Jellesen, Per Møller, Pia Wahlberg, and Rajan Ambat
}

\begin{abstract}
Electrochemical migration behavior of end terminals on ceramic chip resistors (CCRs) was studied using a novel experimental setup in varying sodium chloride concentrations from 0 to $1000 \mathrm{ppm}$. The chip resistor used for the investigation was $10-\mathrm{k} \Omega$ CCR size 0805 with end terminals made of $97 \mathrm{Sn3Pb}$ alloy. Anodic polarization behavior of the electrode materials was investigated using a microelectrochemical setup. Material makeup of the chip resistor was investigated using scanning electron microscopy (SEM)/energy dispersive spectroscopy and focused-ion-beam SEM. Results showed that the dissolution rate of the $\mathrm{Sn}$ and stability of $\mathrm{Sn}$ ions in the solution layer play a significant role in the formation of dendrites, which is controlled by chloride concentration and potential bias. Morphology, composition, and resistance of the dendrites were dependent on chloride concentration and potential.
\end{abstract}

Index Terms-Corrosion testing, electrochemical analysis, environmental testing, failure, tin.

\section{NOMENCLATURE}

\section{CCR Ceramic chip resistor.}

ECM Electrochemical migration.

EDS Energy dispersive spectroscopy.

FIB Focused ion beam.

OCP Open circuit potential.

PCB Printed circuit board.

SCECM Single-component electrochemical migration.

SEM Scanning electron microscopy.

SHE Standard hydrogen electrode.

\section{INTRODUCTION}

$\mathrm{C}$ ORROSION of electronic devices in humid environment is of serious concern today due to the combination of multimaterial use, potential bias, and miniaturization on printed circuit boards (PCBs). Process- and service-related contaminations accelerate corrosion by making the environment more aggressive [1], [2]. Due to corrosion problems, the life span of products is reduced [3], and failure or loss of functionality of devices leads to severe economic loss, plant downtime, and customer dissatisfaction.

Manuscript received December 23, 2008; revised February 9, 2009 and April 2, 2009. First published May 12, 2009; current version published September 2, 2009.

D. Minzari, M. S. Jellesen, P. Møller, and R. Ambat are with the Department of Mechanical Engineering, Technical University of Denmark, DK 2800 Lyngby, Denmark (e-mail: dm@mek.dtu.dk).

P. Wahlberg is with the Department for Micro Technology and Surface Analysis, Technological Institute of Denmark, DK 2630 Tåstrup, Denmark.

Color versions of one or more of the figures in this paper are available online at http://ieeexplore.ieee.org.

Digital Object Identifier 10.1109/TDMR.2009.2022631

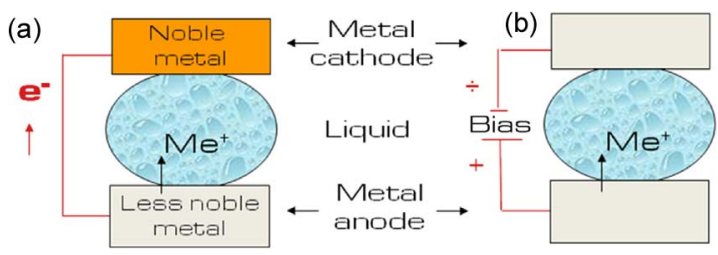

Fig. 1. Two possibilities for corrosion cell formation on a PCB with condensed electrolyte. (a) Galvanic coupling due to different materials on PCB. (b) Formation of electrochemical cell between similar electrodes due to applied bias.

Miniaturization at all levels is one of the key factors reducing corrosion reliability. Over the last ten years, the size of electronics has been reduced by over $70 \%$. For flip-chip ICs, miniaturization amounts to $\sim 90 \%$. The closer spacing increases the electric field ( $E=V / d$, where $E$ is the electric field, $V$ is the applied potential, and $d$ is the distance between the terminals), which makes corrosion cell formation easy during local condensation under humid environments. At constant voltage, the electric field between the conductors rises inversely with the conductor spacing, and corrosion phenomena such as electrochemical migration (ECM) are known to be enhanced under high electric fields [6], [7].

Under humid conditions, a nanoscale water layer is formed locally on the PCB components, giving rise to a conducting path for current flow and thereby establishment of electrochemical cell between two points on PCBs. The potential bias on the PCB at adjacent points or dissimilar material combinations serves as a thermodynamic driving force for the corrosion cell. Fig. 1 shows two possibilities for the corrosion cell formation on the surface of the PCBs due to material combinations and potential bias. Hygroscopic process- and service-related contaminations increases the risk of forming a water layer on the PCB surface along with being a source of ions for solution conductivity.

ECM is a typical form of corrosion found on electronic systems [3], [4] due to the presence of susceptible metals such as $\mathrm{Cu}, \mathrm{Ag}, \mathrm{Sn}, \mathrm{Pb}$, etc. ECM occurs due to the presence of a potential gradient between two susceptible conductors $(\mathrm{Cu}, \mathrm{Ag}$, $\mathrm{Sn}, \mathrm{Pb}$, etc., on $\mathrm{PCB}$ ) connected by a thin layer of solution. For example, two terminals of a chip capacitor or resistor on a PCB could act as anode and cathode if they are connected by a water layer. In this case, dissolved metal ions from the positive electrode (anode) migrate toward oppositely charged negative electrode (cathode) to deposit there. The process is similar to metal plating except for the dendritic morphology of the deposit formation extending from cathode to anode. Growth of dendrites finally leads to electric short between two points on the PCB, which cause component failure or malfunction. 
However, not all metals on the PCB can cause electrolytic migration. Whether a specific metal is susceptible to electrolytic migration or not depends on the stability of the dissolved metal ion in aqueous solution and of the overvoltage required for deposition compared to hydrogen overvoltage. Metal compounds with low solubility product give fewer ions for migration, while those with high hydrogen overvoltage will not deposit. Therefore, on a PCB surface, only metals like $\mathrm{Cu}$, $\mathrm{Ag}, \mathrm{Sn}$, and $\mathrm{Pb}$ are susceptible to ECM at least over a range of potentials and $\mathrm{pH}$ predicted by the Pourbaix diagram [5]. Tin and lead exist in the form of solder alloy on the PCB surface and also as an outer layer of electrodes of components, for example, chip resistors and capacitors. Migration of these metals on a PCB surface leads to malfunction or failure of devices during service.

ECM has traditionally been roughly divided into two subcategories: humid ECM, where a thin invisible moisture film is adsorbed to the surface, and condensed ECM, where a visible layer of condensed water is present [8]. Although Brunauer et al. [9] found an exponential increase in surface conductivity, not all metals that are susceptible to ECM have been found to migrate under humid conditions. Silver and, to some extent, copper have been reported to migrate under humid conditions [10]-[15], while other susceptible metals usually require a visible water layer (condensed conditions) [8], [16]-[26]. However, as distances on the PCBs are getting smaller due to miniaturization, the risk of having a condensation nucleus expanding over two conductors increases, and the relevance for ECM under wet (condensed) conditions is therefore increasing.

The exact mechanism of electrolytic migration and influencing factors on a PCB surface vary from one application to another, and many factors are still unknown. Contaminations such as chloride ions have significant effect on corrosion, while $\mathrm{pH}$ of the solution layer determines the stability of the dissolved metal ions in the water layer for migration to occur [5]. Localized $\mathrm{pH}$ changes are also likely to occur during migration due to water dissociation and hydrolysis at the electrodes.

A problem encountered when investigating ECM phenomenon directly on the PCB is the number of parameters influencing the system such as solder process, solder flux, and heating profile, to name a few. Noh and Jung [1] found that ECM migration is more likely to occur on a glass-epoxy FR-4 (flame resistant-4) PCB than on a polyimide PCB. Yoo and Kim [28] investigated the influence of the corrosion properties on ECM in varying $\mathrm{Pb}$ concentrations. Sample preparation was done by applying a solder paste of varying $\mathrm{Pb}$ content onto a silicon wafer and passing it through a reflow oven. However, the solder paste contains flux, and for varying $\mathrm{Pb}$ content, the flux chemistries could be different and remnants of the solder flux could greatly affect the migration process. In addition, the surface roughness of the solder on a silicon wafer could be different than on a PCB, thereby influencing the ECM behavior [4]. Such factors make reliable reproduction of experiments extremely difficult, thereby complicating interpretation and comparison of experimental results.

In this paper, ECM on ceramic chip resistors (CCRs) in condensing environment has been investigated in detail using a single-component ECM (SCECM) setup in which a single electronic component can be directly loaded and ECM process can be investigated. The setup is attached with a video microscope for in situ observation. In this paper, the effect of chloride ion concentration and potential bias was investigated. Basic electrochemical behavior of the chip resistor electrode materials was investigated using a microelectrochemical setup with a tip diameter of $350 \mu \mathrm{m}$. The material makeup, microstructure, and corrosion morphology were investigated using scanning electron microscope (SEM), energy dispersive spectroscopy (EDS), focused-ion-beam SEM (FIB-SEM), and optical microscopy.

In the SCECM setup, a single chip component can be loaded with applied potential on both sides to be exposed to microvolume environment, thus simulating the condensed corrosion environment encountered on a PCB. The resulting migration current can be monitored together with time-lapse videoing of the migration phenomena. A great advantage of this experimental setup is that the components can be investigated in the as-received condition, without any soldering process. Chloride is known to be an aggressive corrosion promoter. As chloride impurities are commonly found on electronic circuits through dust, handling, or external exposure, it is relevant to investigate the effect it has on ECM. Increased chloride content on a PCB is expected to result in increased kinetics of metal dissolution in a condensed humidity environment. However, the effect of chloride concentration on ECM is not yet understood nor are the synergistic effects of chloride with other impurities on a PCB (i.e., solder flux or dust). The work in this paper focuses on the effect chloride concentration on electrolytic migration behavior. Most electronic components will be exposed to field environments that are mainly humid, and condensed environments are believed to be limited to fewer cases, although the relevance of condensed environments has increased dramatically in the past decade due to the increased mobility of electronic devices. Work is currently underway using the SCECM setup in a humid environment, with and without corrosive gasses, such as $\mathrm{H}_{2} \mathrm{~S}, \mathrm{SO}_{2}$, and $\mathrm{NH}_{3}$. Results from these investigations will be published separately.

\section{MAterials AND Methods}

\section{A. Electronic Components}

The electronic component used for investigation in this work is a commercially available $10-\mathrm{k} \Omega$ CCR size 0805 (Fig. 5). The dimension of the chip resistor is $2.0 \times 1.2 \times 0.45 \mathrm{~mm}^{3}$. The component chosen for this investigation represents a large number of chip resistors used for the electronic PCB production.

\section{B. SCECM System}

The SCECM setup consists of a glass chamber where opposite sides are fitted with two tiny adjustable probes, which acts as connections to each end of the components, in this case chip resistor (Fig. 2). One of the probes is fixed, while the other can be controlled in the transverse direction with micrometer precision. The probes are covered with silicone rubber, which is penetrated by the probe when a load is applied, thereby 
(a)

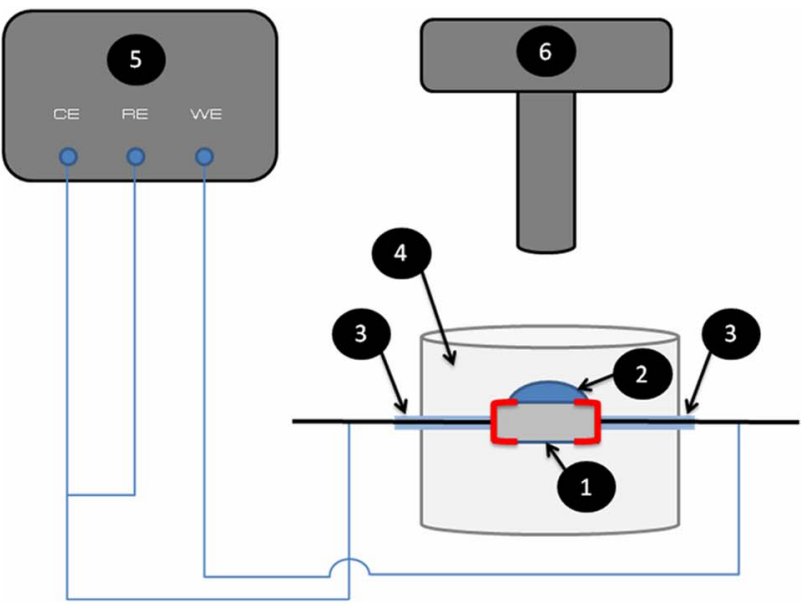

(b)

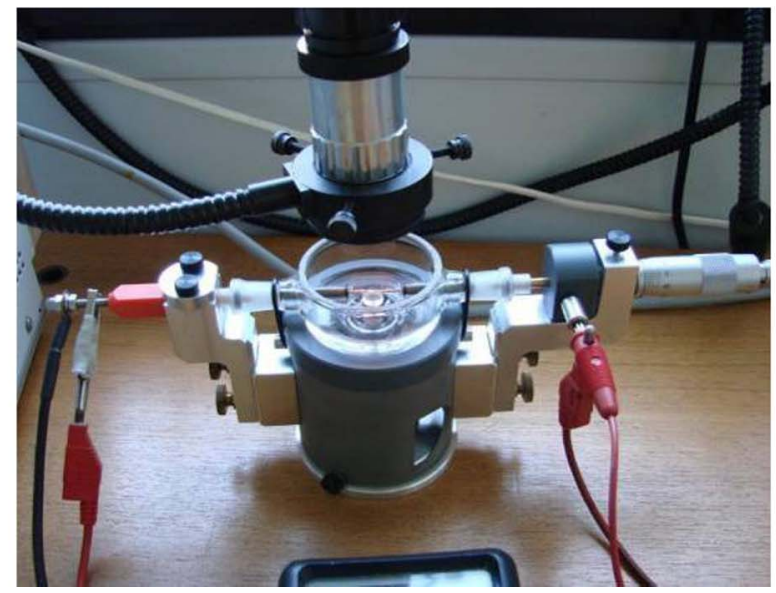

Fig. 2. (a) Schematic of the SCECM setup: (1) Specimen for investigation, (2) droplet of solution, (3) needles covered by silicone for electrical contact, (4) experiment chamber, (5) potentiostat, and (6) video microscope. (b) Image of actual setup.

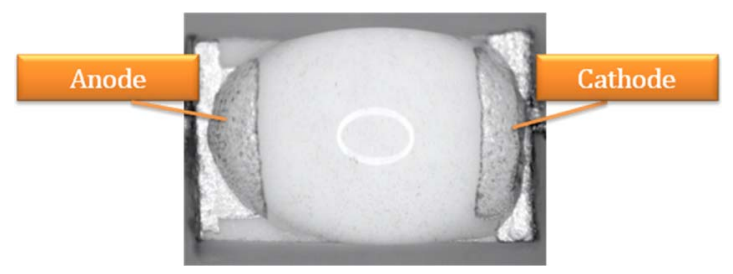

Fig. 3. CCR with water droplet added for simulating local condensation.

allowing electrical contact while, at the same time, providing corrosion protection to the probes.

The potentiostat used for the SCECM experiments was a Gill AC potentiostat from ACM instruments. For 12-V experiments, a current divider was used for increasing the potential output of the potentiostat.

A droplet of solution is then added onto the surface of the resistor (as shown in Fig. 3), and a required dc bias is applied between the two electrodes of the component. Simultaneously, the time-lapse video recording is started (Fig. 2) for in situ videoing of the migration sequence.

Experiments are conducted on the bottom side of the resistor, due to the better color contrast between the dendrite and $\mathrm{Al}_{2} \mathrm{O}_{3}$ substrate, which facilitates in situ visual documentation of dendrite formation.

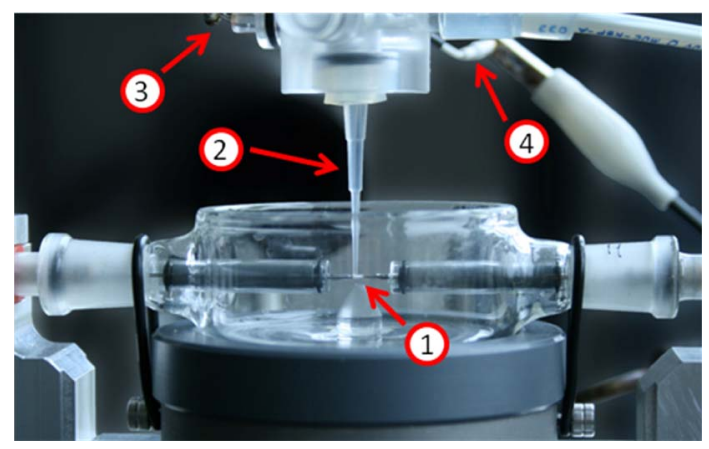

Fig. 4. Microelectrochemical setup used in combination with the SCECM holder: (1) Specimen to be investigated, (2) tip containing electrolyte, (3) connection for counter electrode, and (4) connection for reference electrode.

Leakage current flowing through the water layer is measured as a function of time until a permanent short is observed. During the experiment, the chamber was covered with a glass lid to minimize evaporation of the liquid.

\section{Microelectrochemical Setup}

A microelectrochemical setup was used for potentiodynamic anodic polarization measurements on the resistor terminal in 10100 - and 1000-ppm $\mathrm{NaCl}$ (Fig. 4). The setup consists of an electrochemical head containing the solution, counter, and reference electrodes, which is attached to the carousel of an optical microscope. The cell is connected to a pipette, which makes contact with a local region of the working electrode (e.g., electrodes of the CCR). The lateral resolution of the technique is determined by the dimensions of the pipette tip, in this case $\sim 350 \mu \mathrm{m}$ in diameter. As the electrode area on CCR is small, part of the surface covered by the electrolyte is the $\mathrm{Al}_{2} \mathrm{O}_{3}$ substrate, which is inactive in the electrochemical measurements. By image analysis of corroded specimens, an electrode area of $0.003 \mathrm{~cm}^{2}$ was found.

All microelectrochemical experiments were conducted using a $\mathrm{CH}$ Instruments $600 \mathrm{~B}$ electrochemical analyzer and an $\mathrm{Ag} / \mathrm{AgCl}$ reference electrode $(3 \mathrm{M} \mathrm{NaCl}$ giving a potential of $215 \mathrm{mV}$ versus SHE). Open circuit potential (OCP) was held for $300 \mathrm{~s}$, after which anodic polarization was conducted from OCP -20 to $2000 \mathrm{mV}$ with a scan rate of $2 \mathrm{mV} / \mathrm{s}$. Electrolyte in the microelectrochemical tip was purged between each experiment.

\section{Specimens and Solutions}

For SCECM measurements, chip resistors were handled by polymer tweezers to avoid any mechanical damage during handling. Sodium chloride solutions of concentrations 0, 10100 , and $1000 \mathrm{ppm}$ in deionized water were used for the experiments. All the solutions were prepared using A.R. grade $\mathrm{NaCl}$. All the experiments were carried out in the aerated conditions. Experiments using each set of parameters were repeated for six times to get a statistical average of the behavior.

\section{E. SEM/EDS and FIB-SEM Analysis}

Microstructural characterization of the components before and after SCECM experiments was done using SEM (JEOL 


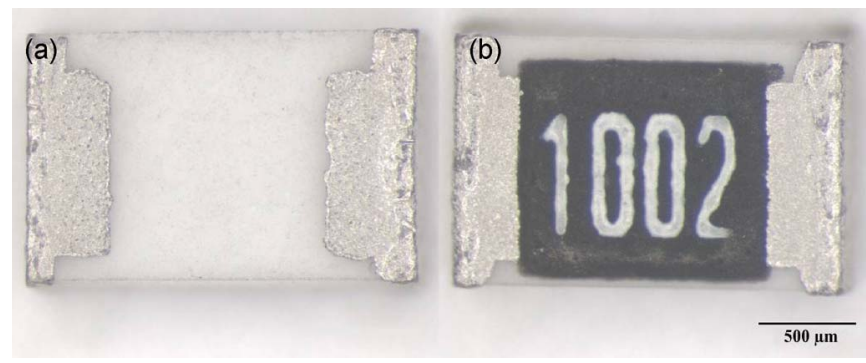

Fig. 5. CCR with size 0805 used in this paper: (a) Bottom side and (b) top side. Resistance of the component is $10 \mathrm{k} \Omega$.

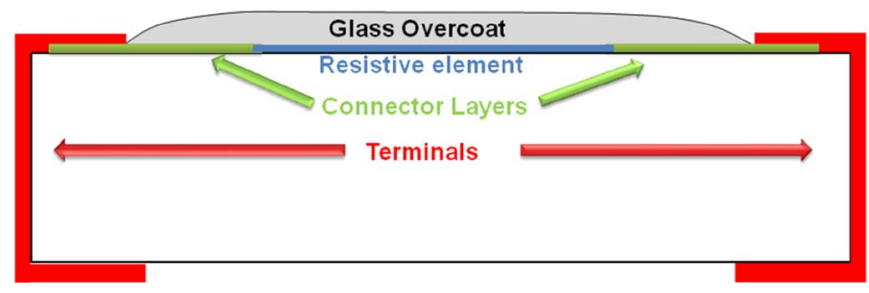

Fig. 6. Schematic of surface mount chip resistor material makeup.

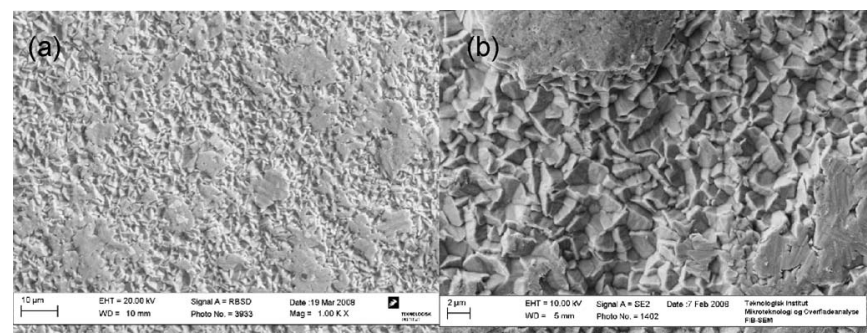

Fig. 7. SEM images of terminal electrode surface layer: (a) Lowmagnification view and (b) high-magnification photograph of rough areas.

5900 instrument), and chemical analysis was carried out using EDS (Oxford Link ISIS) analyzer attached to the SEM. FIB-SEM was performed using a Zeiss 1540EsB cross beam for the cross sectioning of dendrites for detailed investigation of microstructure.

\section{RESULTS}

\section{A. Material Makeup and Microstructure of Chip Resistor}

The CCR (Fig. 5) is a surface mount component that consists of a sintered ceramic body, on top of which a resistive layer is placed.

An inert glass coating is applied in order to protect the resistive layer, and connections to the resistive layer are made by adding metal terminals at the ends of the component. A schematic of the material makeup is shown in Fig. 6.

Fig. 7 shows a SEM photograph of the surface of the electrodes. EDS analysis showed that the top surfaces of the electrodes are made of tin containing $3 \mathrm{wt} \%$ lead $(\mathrm{Sn} 3 \mathrm{~Pb})$. Surface morphology of the electrode shows that the surface is nonuniform, with rough areas indicative of a barrel plating technique used for manufacturing of the outer layer of these resistors.

Fig. 8 shows the cross section of the resistor and different layers of electrode materials and resistive element. Table I
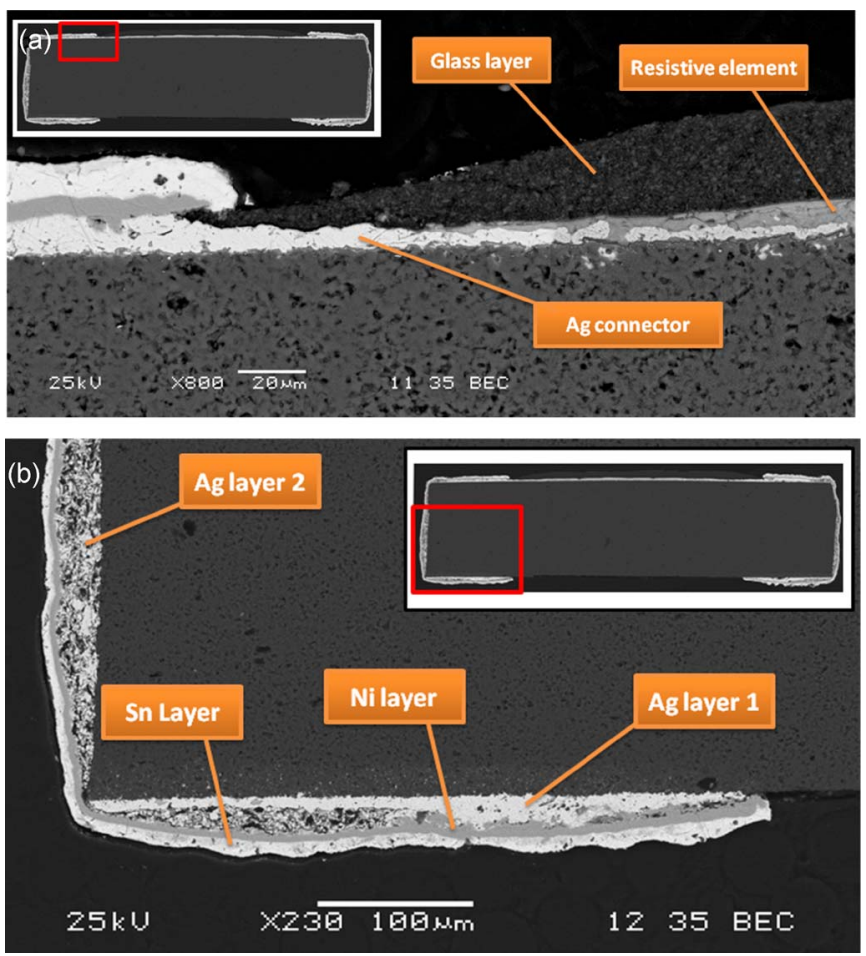

Fig. 8. SEM cross sections of chip resistor: (a) Terminal-resistive element connection and (b) bottom side of terminal. An overview of the whole cross section is shown on each image. The position of the image acquisition is marked by a square.

TABLE I

ELEMENTAL COMPOSITION OF COMPONENT PARTS (All Results in Weight Percent)

\begin{tabular}{|c|c|c|c|c|c|c|c|c|c|c|}
\hline Element & & & & & & & & & & \\
\hline $\begin{array}{l}\text { Comp. } \\
\text { part }\end{array}$ & $\mathbf{O}$ & Al & $\mathbf{S i}$ & $\mathrm{Ca}$ & $\mathbf{T i}$ & $\mathrm{Cr}$ & Sn & $\mathbf{N i}$ & Ag & $\mathbf{P b}$ \\
\hline Terminals: & & & & & & & & & & \\
\hline $\begin{array}{l}* \text { Sn } \\
\text { layer }\end{array}$ & & & & & & & 97 & & & 3 \\
\hline $\begin{array}{l}{ }^{*} \mathrm{Ni} \\
\text { laver }\end{array}$ & & & & & & & & 100 & & \\
\hline $\begin{array}{l}* A g \\
\text { layer }\end{array}$ & & & & & & & & & 100 & \\
\hline $\begin{array}{l}\text { Glass } \\
\text { layer }\end{array}$ & 30 & & 70 & & & & & & & \\
\hline $\begin{array}{l}\text { Resistive } \\
\text { element }\end{array}$ & 9 & 3 & 18 & 1 & 2 & 2 & & & 7 & 58 \\
\hline $\begin{array}{l}\text { Ceramic } \\
\text { Body }\end{array}$ & 29 & 69 & 2 & & & & & & & \\
\hline
\end{tabular}

shows a summary of the EDS analysis of various components with major and minor elements. The resistive layer was analyzed using EDS and was found to contain oxides of $\mathrm{Pb}$ and $\mathrm{Si}$ with smaller amounts of $\mathrm{Ca}, \mathrm{Ti}, \mathrm{Cr}, \mathrm{Zn}$, and $\mathrm{Ag}$. This layer is covered by a silicon oxide glass layer. The Ag layers are used to connect the resistive layer to the terminals that consist of a $\mathrm{Sn} 3 \mathrm{~Pb}$ outer layer on top of Ni layer, which is placed on top of Ag layer. The ceramic body is made of aluminum oxide, with small amount of silicon oxide. Particles containing $\mathrm{Cu}, \mathrm{Ag}$, and $\mathrm{Bi}$ where found at the outer $20 \mu \mathrm{m}$ of the ceramic body, probably impurities from the sintering process. 

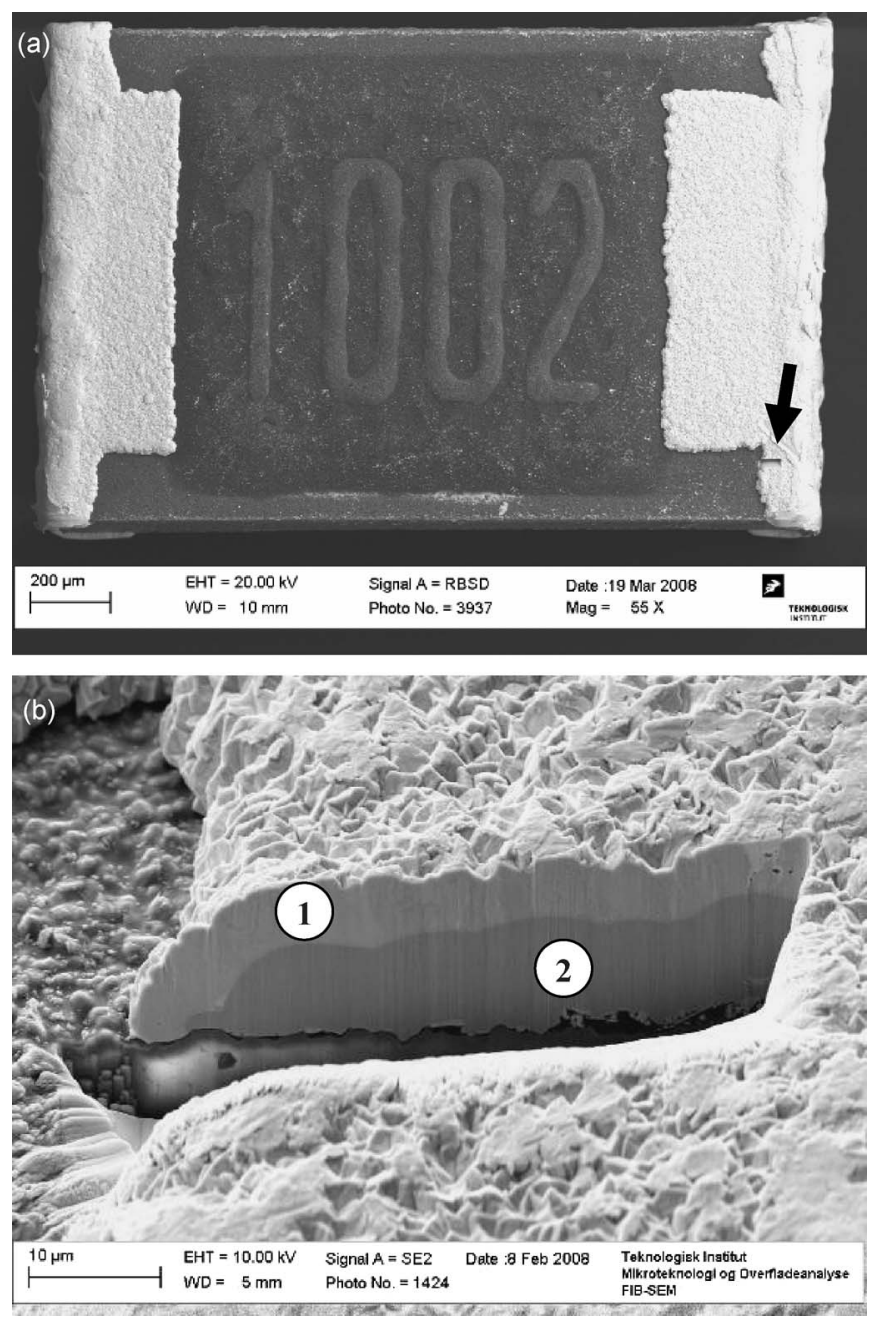

Fig. 9. SEM micrographs of chip resistor: (a) Top side of resistor with FIB cross section (marked by arrow) and (b) high magnification of FIB cross section revealing (1) Sn layer with (2) Ni underlayer.

In order to understand how $\mathrm{Ni}$ and $\mathrm{Ag}$ layers are distributed inside the resistor electrode, an FIB cross-sectional analysis was made, as shown in Fig. 9, on part of the electrode termination area.

The multiple metallic layers can be seen in the FIB cut area with $\mathrm{Ni}$ and $\mathrm{Sn}$ layers as described before. It is also clear that the $\mathrm{Ag}$ and Ni layers are hidden beneath the Sn layer and therefore not exposed to the surface.

\section{B. Anodic Polarization of Component Terminals}

The Tafel plot overlay of the anodic polarization curves for the solder terminal in increasing chloride concentrations is shown in Fig. 10. The current density axis is in logarithmic scale, and therefore, currents are positive irrespective of whether it is cathodic or anodic. The potential value (intersection of both curves) where the current changes from negative to positive (or the potential value at which the cathodic current is equal to the anodic current) is called the steady-state corrosion potential $E_{\text {corr. }}$. This can be seen on the curves as a "notch" at potentials between -200 and $-400 \mathrm{mV}$. At potential less than these values, the current is negative, and the surface is in the

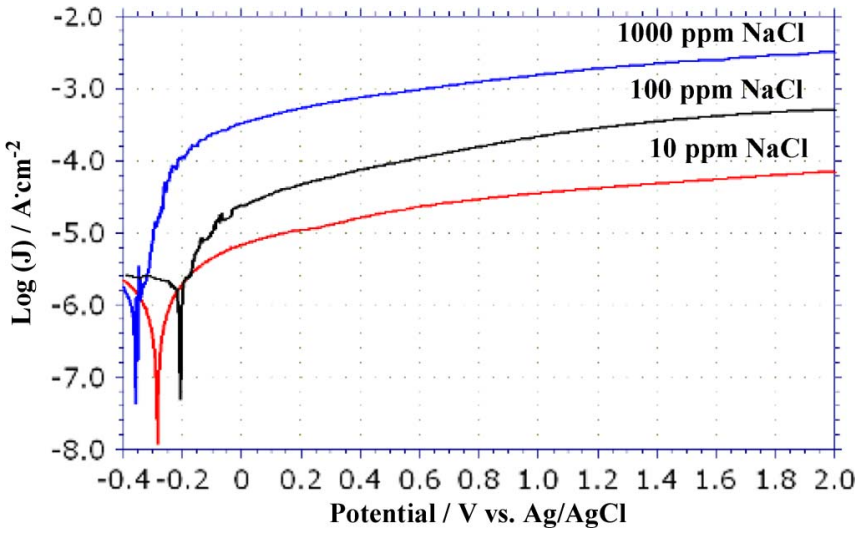

Fig. 10. Anodic polarization curves for solder terminals on CCR. The $Y$-axis is showing the logarithm to the current density (in joules), and the $X$-axis has the potential versus $\mathrm{Ag} / \mathrm{AgCl}$ reference electrode ( $215 \mathrm{mV}$ versus SHE).

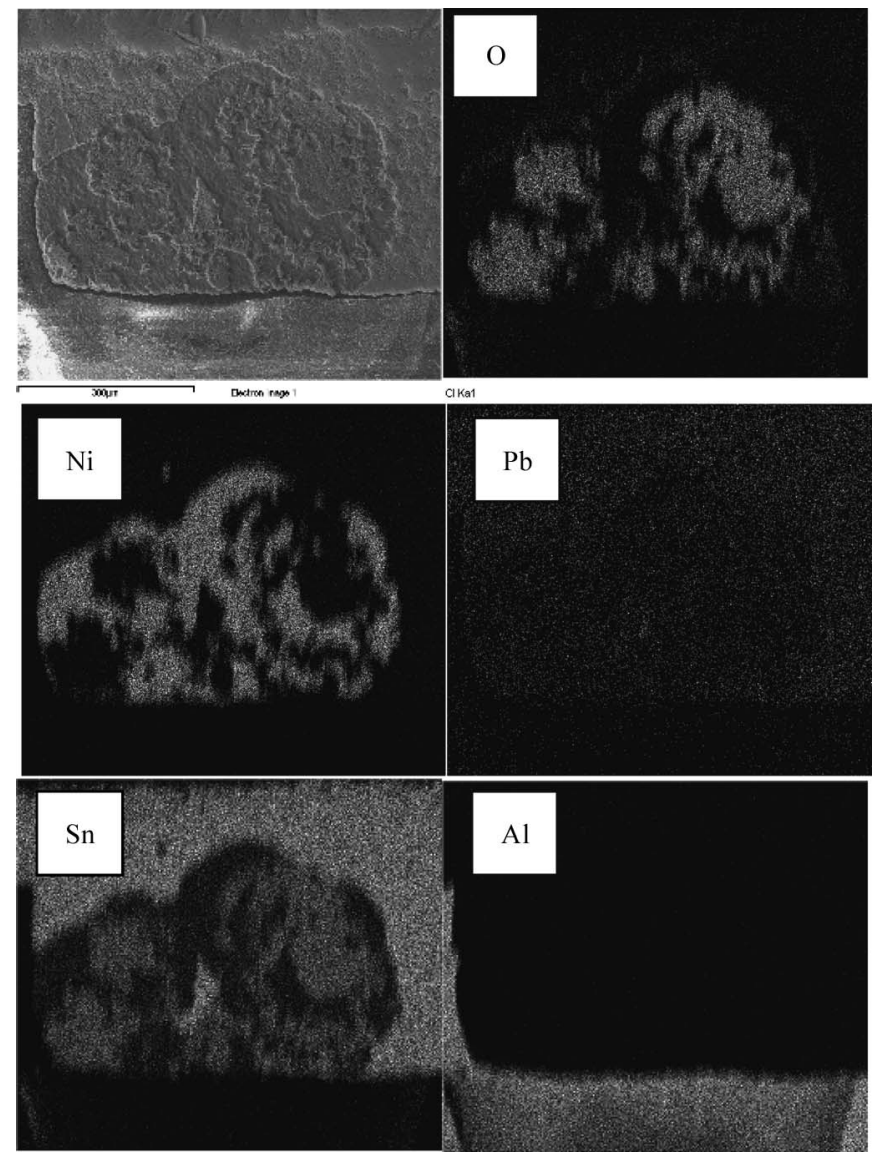

Fig. 11. (Top left) SEM image of corroded area after anodic polarization in 1000 -ppm $\mathrm{NaCl}$ to $2000 \mathrm{mV}$ versus $\mathrm{Ag} / \mathrm{AgCl}$ electrode. (Rest) EDS mappings showing $\mathrm{O}, \mathrm{Ni}, \mathrm{Pb}, \mathrm{Sn}$, and $\mathrm{Al}$ signals.

cathodic domain. At potentials larger than $E_{\text {corr }}$, the current is positive, and anodic dissolution of tin is observed. Active dissolution of tin is observed upto a potential of approximately $E_{\text {corr }}+100 \mathrm{mV}$. Above this value, current flattens as the ohmic limit of the solution is reached. The dissolution rate of the tin is seen to increase with the chloride concentration. Almost a decade increase in current was observed with ten times increase in chloride concentration. At high potentials, polarization curves flatten as the ohmic limit of the solution 

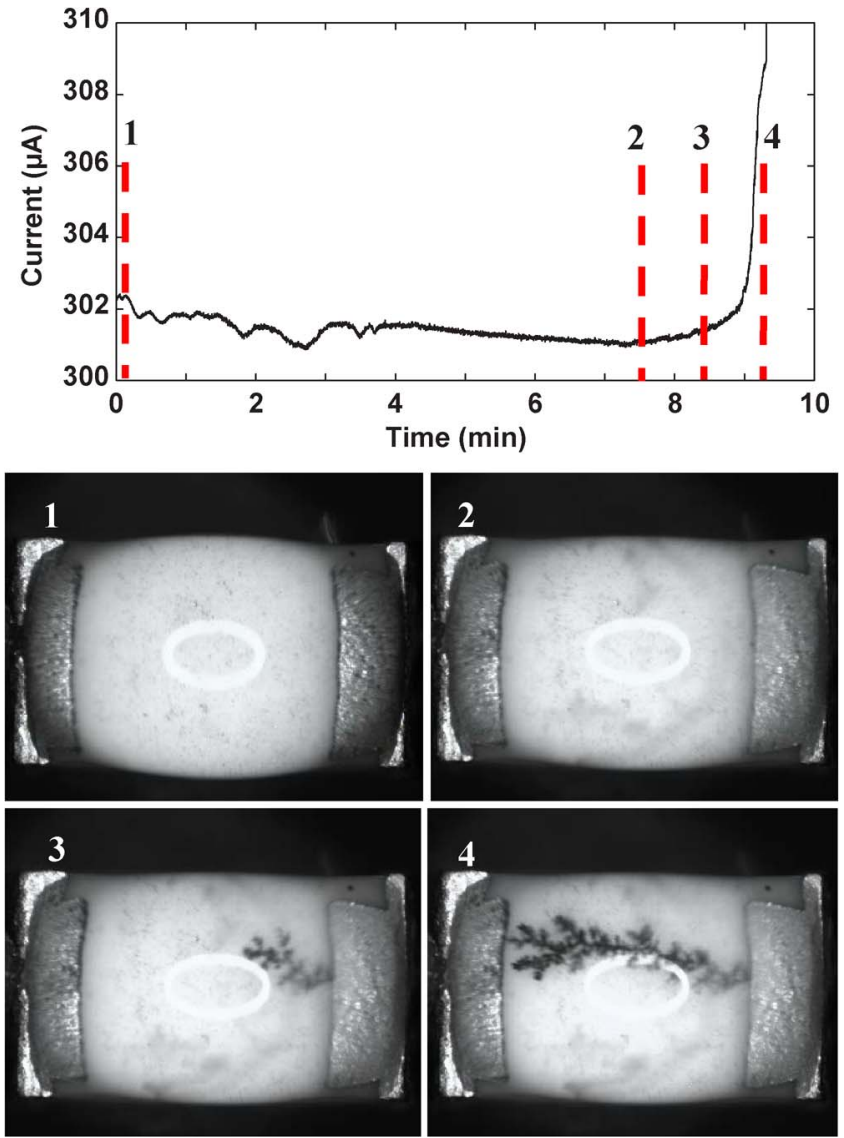

Fig. 12. Current-time curve for dendrite formation during SCECM experiment in 10-ppm $\mathrm{NaCl}$ solution at $3-\mathrm{V}$ bias, along with images of the various stages of dendrite formation. For all images, cathode is on the right and anode is on the left. The times of image acquisition are marked by dotted lines on the current-time curve.

is reached, and little increase in current density is seen with increase in potential.

Corroded area after 1000-ppm $\mathrm{NaCl}$ anodic polarization experiment was investigated using SEM and X-ray mapping, as shown in Fig. 11. The X-ray mapping clearly shows selective dissolution of tin exposing nickel layer beneath. Islands containing higher amount of tin and oxygen are seen, probably corrosion products.

\section{Electrolytic Migration Experiments in Chloride Solutions}

1) Migration as a Function of Time in 10-ppm NaCl Under a 3-V Bias: Fig. 12 shows the current-time curve along with images of the dendrite formation as a function of time in 10 -ppm $\mathrm{NaCl}$ in DI water under 3-V bias. Before application of the solution, the base current level was measured to $300 \mu \mathrm{A}$, as expected for a $10-\mathrm{k} \Omega$ resistor at $3-\mathrm{V}$ bias.

Image 1 in Fig. 12 shows the initial condition, just as the potential bias was applied, as illustrated by the dotted line added to the current-time curve. First visible dendrite nucleation was observed after approximately $7 \mathrm{~min}$ and $30 \mathrm{~s}$ (image 2). At this stage, a little corrosion is observed at the anode, and some corrosion products are seen in the solution, most likely tin hydroxides. After the first visible nucleation of a dendrite was observed, a period of approximately 2 -min dendrite growth was
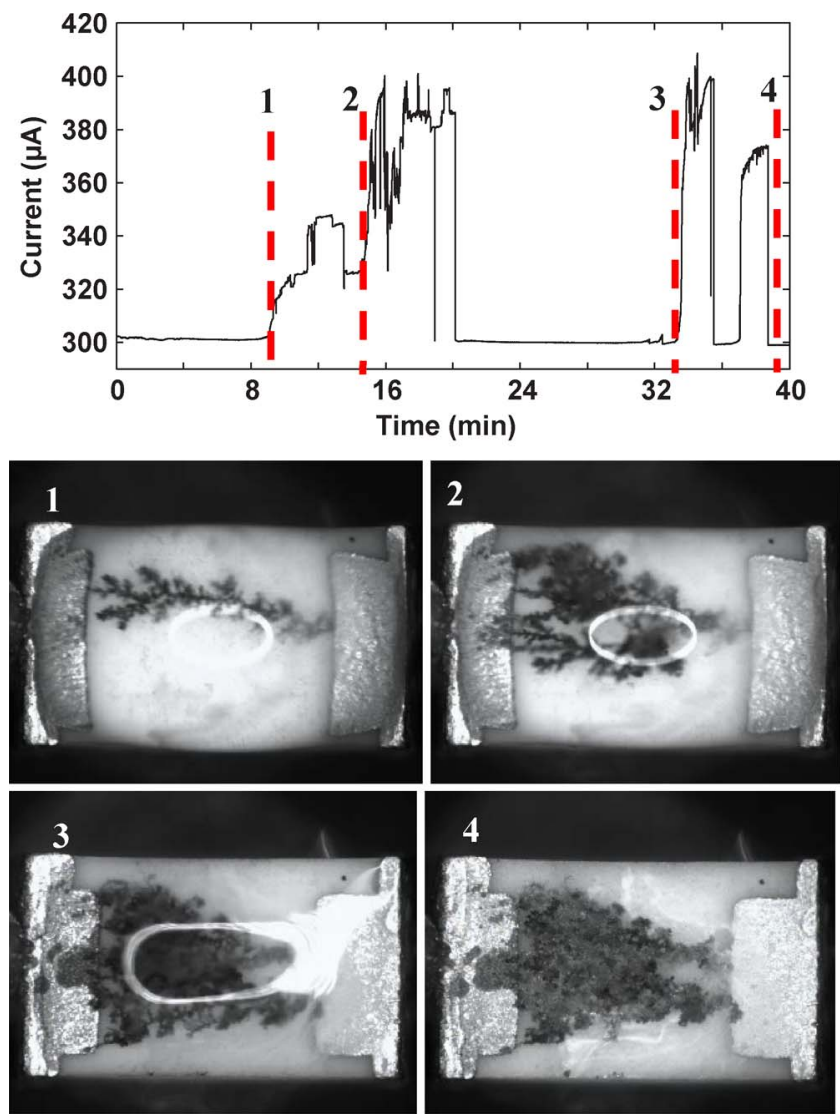

Fig. 13. Current-time curve for dendrite formation until electrolyte has evaporated for $10-\mathrm{ppm} \mathrm{NaCl}$ at $3-\mathrm{V}$ bias experiment, along with images at selected stages. For all images, cathode is on the right and anode is on the left. The times of image acquisition are marked by dotted lines on the current-time curve.

observed (image 3) until the dendrite finally reached the anode short-circuiting the system (image 4).

The current-time curve for the whole experiment is shown in Fig. 13 along with images of dendrite at the time of first short (image 1), condensation (images $2+3$ ), and at the end of the experiment where the solution has dried out (image 4).

The dendrite is seen to increase the current to the level of $400 \mu \mathrm{A}$ until the dendrite bridge degrades (burns off) at approx time $=20 \mathrm{~min}$. At this stage, current drops back to the base level of $300 \mu \mathrm{A}$. After $33 \mathrm{~min}$, a new dendrite bridge is formed, which again degrades, and this behavior continues until the solution is completely evaporated from the component.

2) Effect of Chloride Concentration and Potential Bias: Figs. 14 and 15 show specimens after SCECM experiments at 3 and $12 \mathrm{~V}$, respectively, and in varying chloride concentrations. Images are acquired at the time where the dendrite first reaches the anode. For experiments with no migration, the image presented is taken after the experiment has finished and the solution has dried out.

At $3 \mathrm{~V}$, dendrite formation was observed even at $0-\mathrm{ppm}$ sodium chloride, while at $12 \mathrm{~V}$, no migration was observed. In addition, at 1000-ppm sodium chloride, experiments at $3 \mathrm{~V}$ did not show dendrite formation, while formation of dendrite was observed at $12 \mathrm{~V}$. Dendrites formed at $12 \mathrm{~V}$ in general were thinner and less branched than those observed at $3 \mathrm{~V}$. 

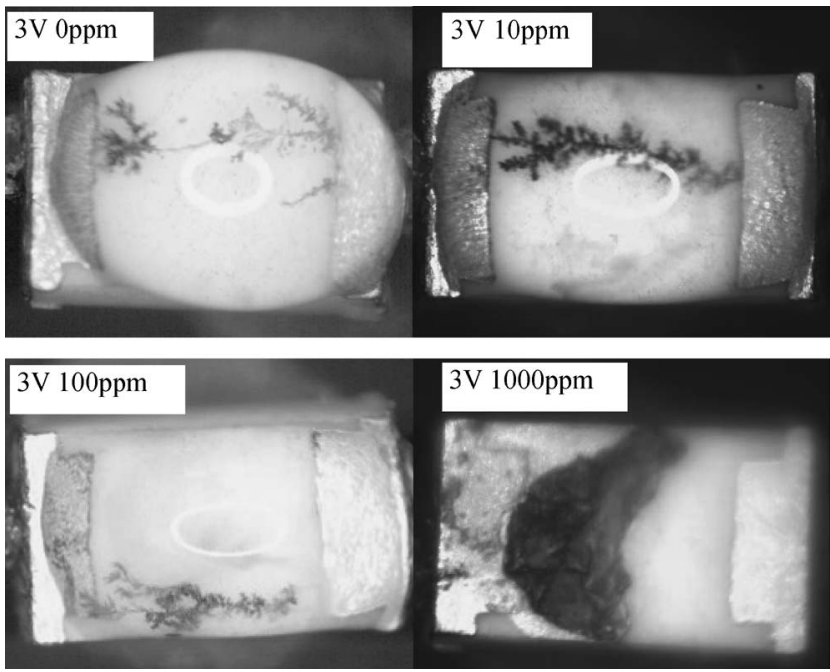

Fig. 14. Dendrite and corrosion morphology for 3-V experiments in varying sodium chloride concentrations. For all images, cathode is on right and anode is on left. For experiments with no migration, the image presented is taken after the experiment has finished and the solution has dried out.
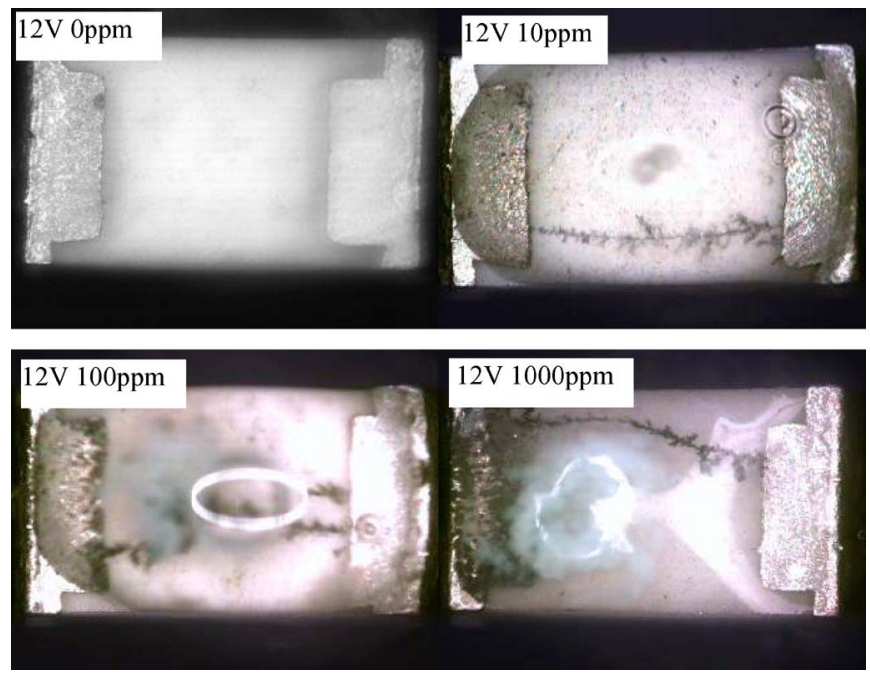

Fig. 15. Dendrite and corrosion morphology for $12-\mathrm{V}$ experiments in varying sodium chloride concentrations. For all images, cathode is on right and anode is on left.

For $12-\mathrm{V}$ experiments using $100-$ and $1000-\mathrm{ppm} \mathrm{NaCl}$, a gray/turquoise corrosion product can be seen (Fig. 15). The EDS analysis showed presence of $\mathrm{Ni}, \mathrm{Sn}$, and $\mathrm{O}$, indicating that the corrosion product is a mixture of hydroxides of these. However, Ni was not detected in the dendrites.

The probability of experiencing a short due to dendrite formation during the experiment time is shown in Fig. 16, and the time for first short circuit is shown in Fig. 17. These data are deduced from the current-time curves obtained during the migration experiments and represent the average of six experiments carried out in each case (similar to the current-time curve in Fig. 13).

It can be observed that the ECM is most likely to occur at sodium chloride concentrations in the range of 10-100 ppm (Fig. 16), while higher values of sodium chloride concentrations result in heavy corrosion of the anode with less tendency

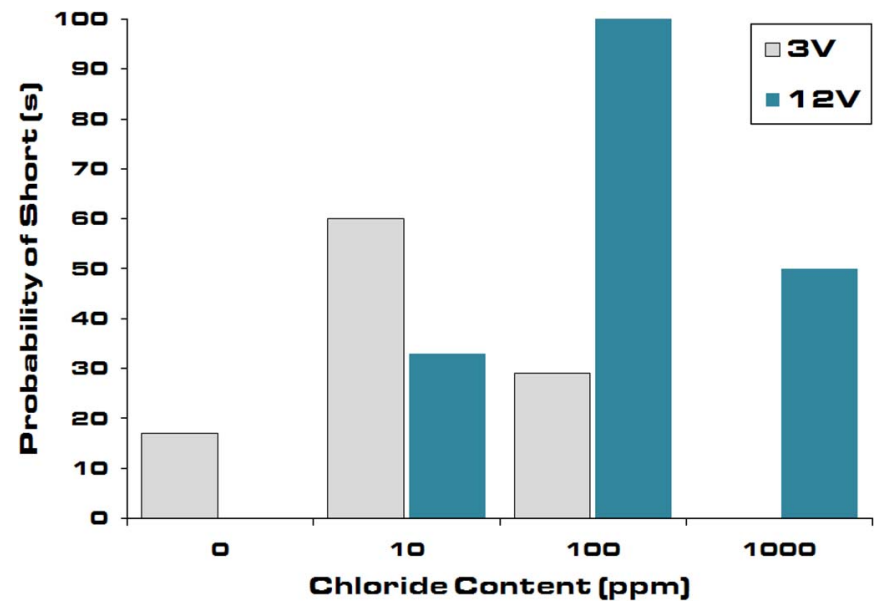

Fig. 16. Probability of ECM for 3 and $12 \mathrm{~V}$ at varying sodium chloride concentrations.

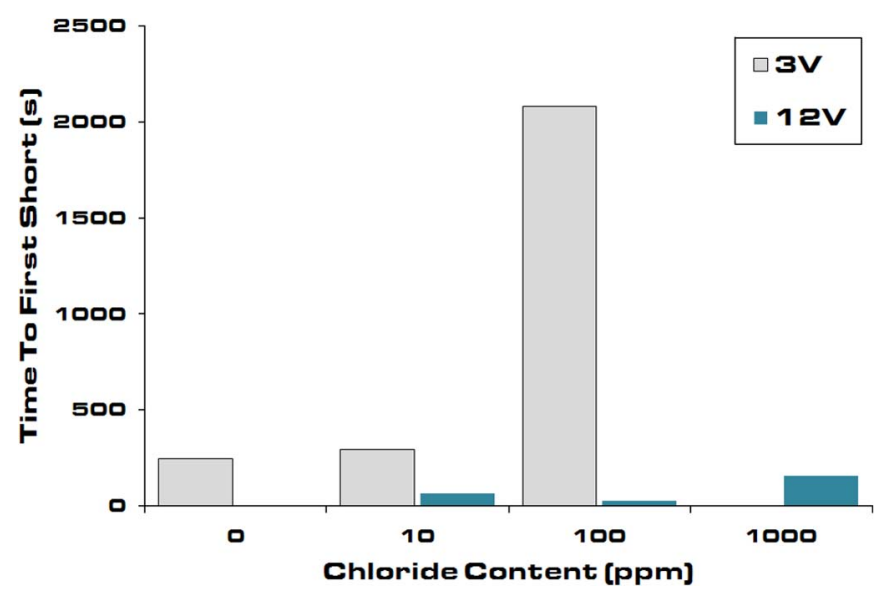

Fig. 17. Time for first short circuit due to ECM for 3 and $12 \mathrm{~V}$ at varying sodium chloride concentrations.

of dendrite formation (see images in Figs. 14 and 15). Repeated experiments with 0 -ppm $\mathrm{NaCl}$ (DI water) on various components have shown that migration is rare, but could happen (at both 3 and $12 \mathrm{~V}$ ). It could be argued that the one experiment in 0 -ppm $\mathrm{NaCl}$, which showed migration, should be excluded as a statistical abnormality. However, we have chosen to include this experiment to show that even at very small contaminations could lead to migration. The origin to these contaminations could be impurities from the manufacturing process, although further investigation is needed to prove this fact.

Fig. 17 shows the time for first short deduced from the current-time curves. The time required for short-circuiting, in general, is longer for the $3-\mathrm{V}$ compared to $12-\mathrm{V}$ bias (Fig. 17). No values are shown for $0-\mathrm{ppm} 12-\mathrm{V}$ and $1000-\mathrm{ppm} 3-\mathrm{V}$ experiments since no migration was observed for these experiments.

3) Electrical Properties of Dendrites as a Function of Potential Bias and Chloride Concentration: The current-time curves for various experiments at 3- and $12-\mathrm{V}$ biases are shown in Fig. 18. Current passing through the electrolyte is very small compared to that passing through the dendrite bridge, and dendrite formed at 3 and $12 \mathrm{~V}$ showed large differences in the capacity for current flow. 


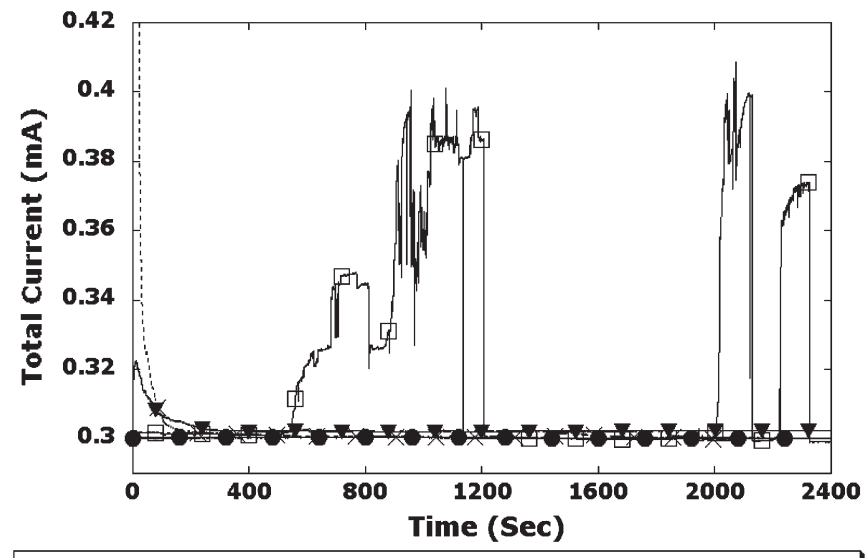

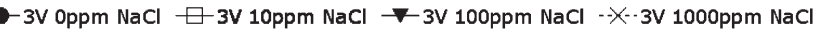

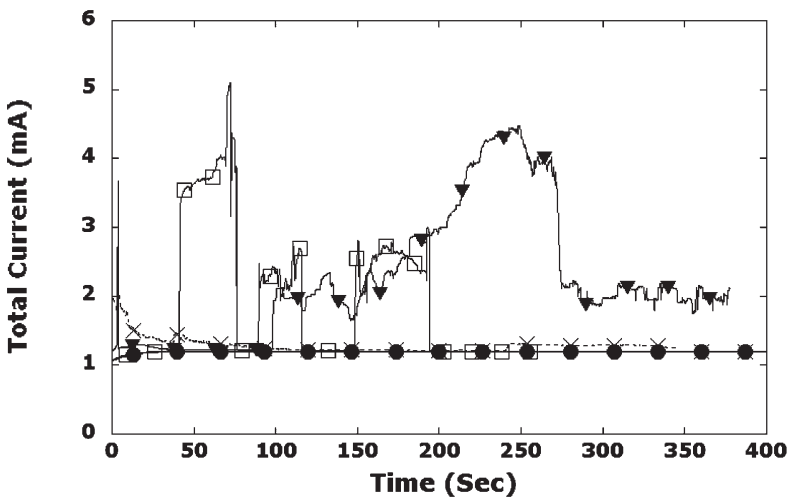

$-12 \mathrm{~V} 0 \mathrm{ppm} \mathrm{NaCl} \quad \square 12 \mathrm{~V} 10 \mathrm{ppm} \mathrm{NaCl} \quad \boldsymbol{\nabla} 12 \mathrm{~V} 100 \mathrm{ppm} \mathrm{NaCl} \quad-\Varangle-12 \mathrm{~V} 1000 \mathrm{ppm} \mathrm{NaCl}$

Fig. 18. Current-time curves for 3 and $12 \mathrm{~V}$ at varying sodium chloride concentrations.

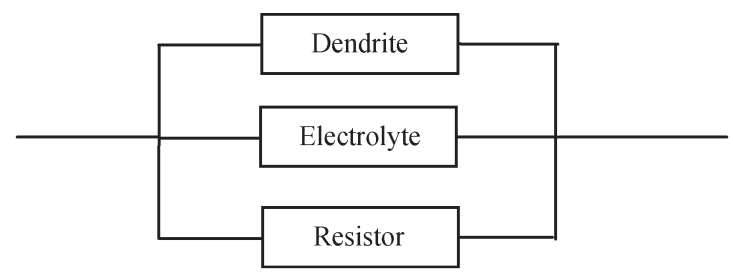

Fig. 19. Simple equivalent circuit for the resistor-electrolyte-dendrite system.

As the dendrite is formed on the surface of the component, the system can be simplified into an equivalent circuit consisting of parallel resistances as shown in Fig. 19.

As the resistance of the electrolyte is very high compared to the resistance of resistor and dendrite, this can be neglected. The resistance of the dendrite can then be roughly estimated using simple Ohms law to provide quantitative estimates.

In order to estimate the resistance or conductivity of the dendrite, the maximum current measured during the experiments was used. Fig. 20 shows the dendrite resistance as a function of the chloride concentration. Values shown are average values only taken from experiments where dendrite formation was observed.

The backbone of a typical dendrite has been observed to be in the magnitude of $\sim 200 \mathrm{~nm}$ (see Fig. 21).

This backbone is the continuous line carrying the current from one terminal to the other. Approximating the dendrite to a

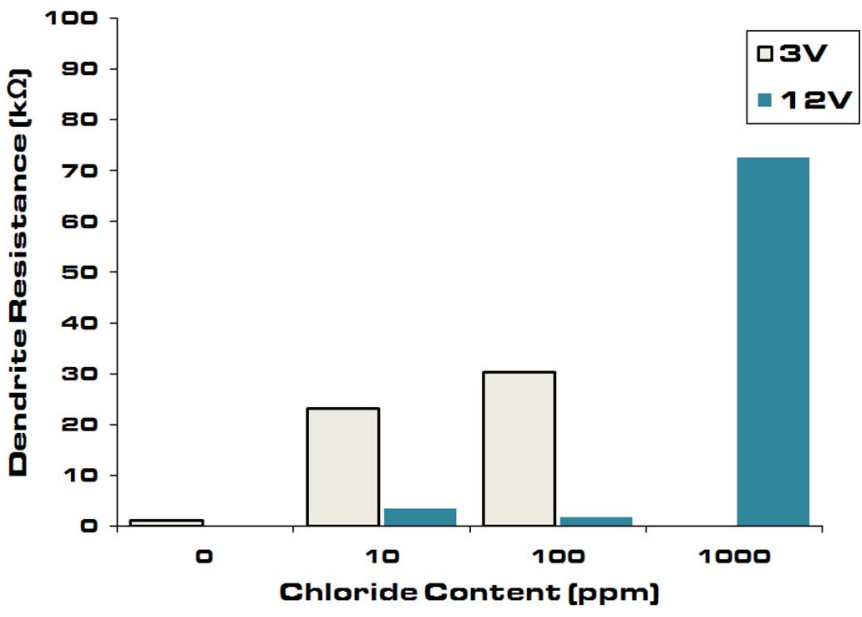

Fig. 20. Dendrite resistance at varying sodium chloride concentrations for 3- and 12-V experiments.

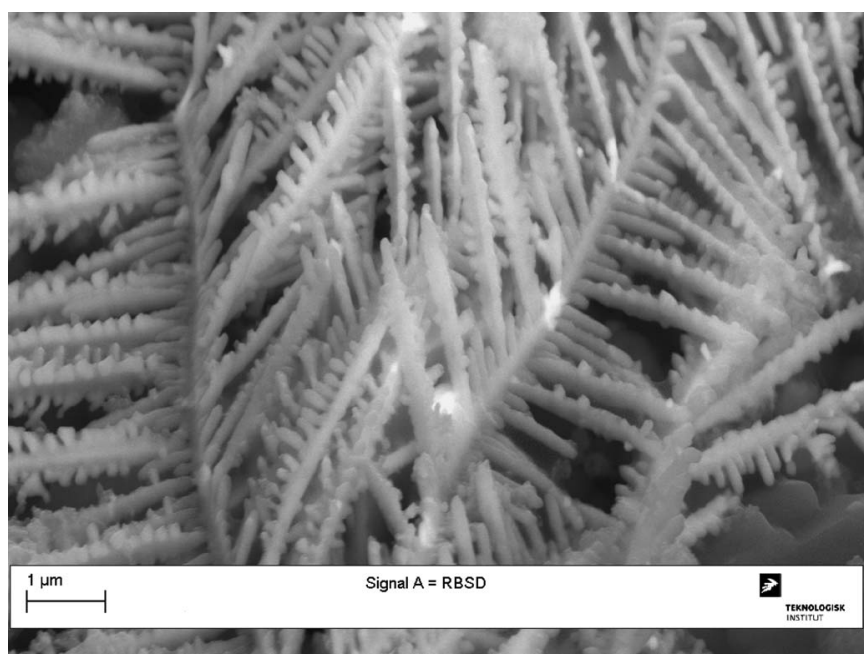

Fig. 21. Example of SEM image of dendrite at high magnification.

wire with a diameter of $200 \mathrm{~nm}$ and a length of approximately $1 \mathrm{~mm}$ (distance between the two terminals on the resistor), a dendrite made of metallic tin should have a resistance of about $3.5 \mathrm{k} \Omega$ (resistivity of tin used is $\sim 1.09 \cdot 10^{-7} \Omega \cdot \mathrm{m}$ ). This value fit quite well with the lowest resistances observed in the magnitude of $1 \mathrm{k} \Omega$, when it is considered that the dendrite does not consist of one backbone but several branches, thereby lowering the resistance. However, many dendrites were observed to have resistances in the scale of 20-75 k $\Omega$, and here, it is particularly noted that for dendrites having high resistances at $3 \mathrm{~V}, 10-100-\mathrm{ppm} \mathrm{NaCl}$ were the ones that appeared thicker as compared to those at $12 \mathrm{~V}$ (see Figs. 14 and 15).

In order to get an idea of dendrite life and cumulative damage to the component, the total charge that passed during the experiments was calculated by integrating the current-time curves. Fig. 22 shows the results obtained at 3 and $12 \mathrm{~V}$. The values were obtained by assuming the baseline to that of the current level for a dry resistor and then integrating the current exceeding that level. As the current contribution from the faraday current through the electrolyte is very small compared to that when a dendrite makes a short (Fig. 18), 


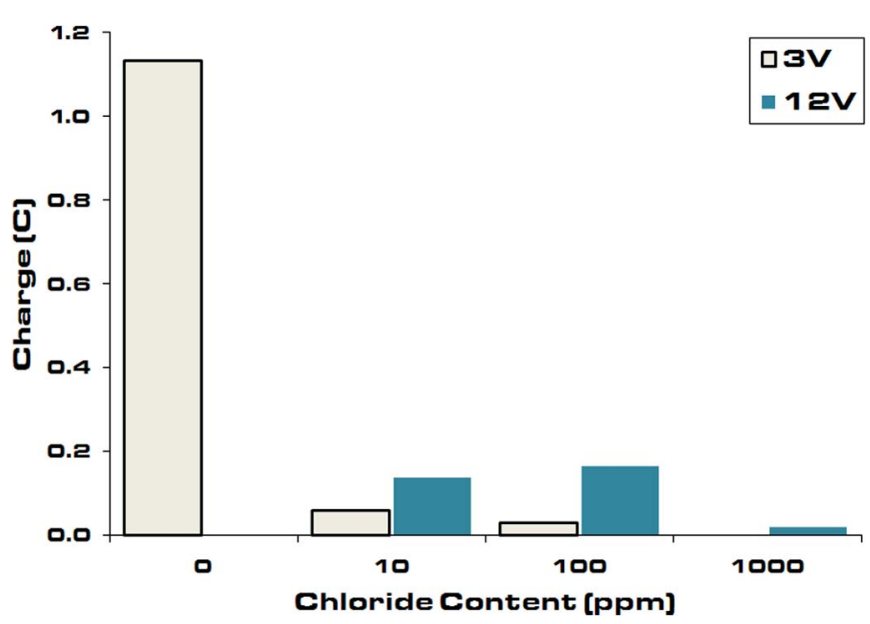

Fig. 22. Charge passing through the dendrites during experiment at varying sodium chloride concentrations for 3 - and $12-\mathrm{V}$ experiments.

this calculation can practically be regarded as the charge that passed through the dendrite. An interesting observation is that, at higher chloride concentrations, the total charge that passed is less due to intermittent burning of the dendrite once it is formed.

\section{Discussion}

Chip resistors tested in this investigation were found to be susceptible to electrolytic migration in chloride environments due to the presence of susceptible electrode materials. Susceptibility to migration, dendrite morphology, and dendrite resistance were a function of the chloride content and potential bias. Results showed some scatters in migration behavior for similar components, with some of them showing dendrite formation while others not, although test parameters were kept similar. This clearly indicates the variability that could be observed on a PCB if many components are present. Therefore, experiments in each case were repeated several times, and the results reported in this paper represent typical behaviors observed.

Migration was observed in one out of six experiments at 0 -ppm $\mathrm{NaCl}$ (pure DI water) using 3-V potential bias, while no migration was observed at $0-\mathrm{ppm} \mathrm{NaCl}$ at $12-\mathrm{V}$ bias. However, it is likely that the migration is due to an uncontrolled parameter, such as impurities from manufacturer of the components.

Overall, the probability of experiencing a short was found to increase initially with change in sodium chloride concentration from 0 to $10 \mathrm{ppm}$ at $3 \mathrm{~V}$, but further increase in concentration reduced the probability for short. Similar behavior was observed at $12 \mathrm{~V}$ except for the shift in the sodium chloride concentration to $100 \mathrm{ppm}$. It is clear from the polarization curves that increased sodium chloride ion concentration increases the dissolution of the anode on the chip resistor. However, it is assumed that the increased metal ion concentration in the solution layer will result in precipitation of hydroxides as the product of concentration of metal ions and hydroxyl ions reaches above the solubility limit. Local changes in $\mathrm{pH}$ (alkalization at the cathode) can assist this process by increasing the hydroxyl ion concentration. Formation of hydroxides impedes migration as hydroxides are neutral compounds, and therefore, they will not migrate under the electric field. Further investigation is needed to elucidate the exact reason for this behavior, but it appears to be due to the change in local $\mathrm{pH}$ change resulting from increased faradaic reactions with bias voltage and corresponding change in the stability of the metal ions. At $12-\mathrm{V} 1000-\mathrm{ppm} \mathrm{NaCl}$, migration still occurred in $50 \%$ of the experiments, whereas at 3-V 1000-ppm $\mathrm{NaCl}$, no migration was observed, but heavy corrosion of the anode was observed (see Figs. 14-16). As shown in the anodic polarization curves, presented in Fig. 10, the anodic dissolution of tin is at the diffusion limited region at both 3 and $12 \mathrm{~V}$. The migration observed at $12 \mathrm{~V}$ could therefore be explained by difference in the local $\mathrm{pH}$ distribution inside the droplet or due to the codissolution of nickel from the terminal underlayer, which could possibly have an effect on the stability of tin ions in the solution, although no evidence is readily given for this at present. However, this might suggest that the migration behavior is influenced by the tin-layer thickness and the morphology of the metal underlayers.

Noh et al. [27] found that the tendency for ECM followed the same trend as the rate of corrosion on materials such as electroless Ag, electroplated Sn, and ENIG (electroless nickel on immersion gold) surfaces when comparing ECM experiments using DI water to corrosion experiments in $1.0 \mathrm{wt} \% \mathrm{NaCl}$ solutions and that the tendency for ECM for various metals was in the order $\mathrm{Ag}>\mathrm{Sn}>\mathrm{ENIG}$. In this paper, however, it is found that the dissolution rate at the anode under ECM conditions plays a significant role on whether ECM is possible or not. In addition, an Ag underlayer is present on the electrode terminal of the CCR used in the present work, but no silver migration or silver corrosion products were observed. This shows that even though silver has a higher trend for ECM, when combined with $\mathrm{Sn}$ and $\mathrm{Ni}$, the galvanic coupling between $\mathrm{Sn}, \mathrm{Ni}$, and $\mathrm{Ag}$ layers might not allow dissolution of silver ions.

Yoo and Kim [28] have investigated the influence of varying $\mathrm{Pb}$ content on ECM using $\mathrm{NaCl}$ and $\mathrm{Na}_{2} \mathrm{SO}_{4}$ solutions (all neutral $\mathrm{pH}$ conditions). In $\mathrm{Na}_{2} \mathrm{SO}_{4}$, the tendency for ECM is seen to decrease due to passivation of $\mathrm{Pb}$, while in $\mathrm{NaCl}$ solution, no significant change in the tendency for ECM is observed when the $\mathrm{Pb}$ content is increased. The $\mathrm{NaCl}$ solution used by Yoo and Kim was 0.001 wt.\% equivalent to the $100-p p m$ solution used in the present work. The time to failure of pure tin in 100-ppm $\mathrm{NaCl}$ at $3-\mathrm{V}$ potential bias found by Yoo and Kim was approximately $60 \mathrm{~s}$, differing significantly from the values found in the present work (Fig. 17). However, the distance between the electrodes used by Yoo and Kim was $350 \mu \mathrm{m}$, whereas the distance between the electrodes in the present work is $1100 \mu \mathrm{m}$. This strongly illustrates the importance of conductor spacing when investigating ECM. Further work is presently carried out, investigating ECM on a large number of components having varying sizes with varying potential bias and environments.

Another important aspect is the morphology and resistance that determine the stability and current leakage through the dendrites. Fig. 20 clearly shows the variations in the resistance values of the dendrites, indicating the possibility of variation in composition of the dendrites formed at different parameters. Increased dissolution kinetics at higher chloride 
concentrations results in more dissolution of tin ions as explained before. Higher concentration of tin ions in the solutions results in precipitation of tin hydroxide, which could be incorporated into the dendrite to increase its resistance. Incorporation of the hydroxide particles changes morphology and resistance of the dendrites. Attempts have been made to analyze the dendrite composition after migration experiments in various $\mathrm{NaCl}$ concentrations using EDS, but due to the large sampling volume of the X-rays produced (approximately $1 \mu \mathrm{m}^{3}$ ), no conclusive results can be presented. The problem is more complicated due to the large variations in the dendrites formed, since dendrite growth conditions could change due to electric field and $\mathrm{pH}$ changes within the droplet. It is believed that the dendrite consists of an inner metallic conductor, embedded by hydroxides or hydrochlorides. Further analysis is underway on investigating dendrite morphology using FIB-SEM and EDS.

Electrolytic migration and dendrite formation observed with no chloride (pure DI water) are assumed to be due to low levels of residues from the surface of the component, which dissolve into the water droplet. It clearly indicates risk of electrolytic migration in actual practice where only very low amounts of residues are sufficient to cause ECM if there is suitable potential bias. Increased amounts of chlorides or other ions will further accelerate the migration process, while the contamination on the components themselves can produce migration if water layer is present.

At higher potentials, it seems that the dendrites are thinner and less branched compared to that at lower potentials. This behavior is believed to be due to the higher electric field acting between terminals, which results in subsequent deposition of the metal ions at the tip of the dendrite rather than branching.

As expected, the time to first short was found to be longer at lower potentials $(3 \mathrm{~V})$ compared to that at $12-\mathrm{V}$ bias due to slow dissolution and deposition kinetics. In addition, the droplet used for 3-V experiments had less tendency to evaporate, indicating less generation of heat in the component (resistor heating) during the experiment. Both aspects correlate with the use of higher voltage that results in higher current through the resistor to heat up, and higher voltage also increases the migration kinetics.

In general, electrolytic migration of the chip resistor was found to be a function of the amounts of chloride ions in solutions and potential bias between electrodes. Presence of chloride ions also increases the dissolution of the anode to provide the metal ions necessary for migration. This is important as the analysis of many field failures shows signs of chloride contamination on the components. Such contamination on a PCB can arise from the use of halide-containing flux, human handling, or from service environments. Material makeup, surface morphology of electrode layer, and solution chemistry all play a big role in controlling migration due to combined effects. Humidity absorption is easy on a rough surface, while dissolution of the top layer of a component electrode can expose the metal underneath causing galvanic corrosion, particularly if the potential bias is switched off. Similarly, the continuous changes in solution chemistry during the experiments determine the stability of dissolved ions in solution. As shown before, the stability of metal ions in the solution layer can alter migration and dendrite formation behavior as well as the resistance of the dendrites.

\section{CONCLUSION}

1) Chip resistor electrode terminals are found to be susceptible to electrolytic migration in sodium chloride solutions under potential biases of 3 and $12 \mathrm{~V}$.

2) Sodium chloride concentrations around $10-100 \mathrm{ppm}$ were found to significantly increase the probability of ECM, depending on the potential bias. Chloride concentration also increased the anodic reactivity of the electrode material.

3) Lower migration kinetics at $3-\mathrm{V}$ experiments resulted in higher time-to-short values. The dendrites formed at $3 \mathrm{~V}$, in general, had higher resistance than those formed at $12 \mathrm{~V}$.

4) SCECM setup was found to be a good tool for corrosion studies of single electronic component in condensing environments.

\section{ACKNOWLEDGMENT}

The authors would like to thank the project partners Danfoss $\mathrm{A} / \mathrm{S}$, Grundfos A/S, Vestas A/S, and GPV Chemitallic A/S; Danish Technological Institute; and IPU for their commitment to this project. Current research has been conducted as part of the CELCORR consortium. The authors would also like to thank the Danish Ministry of Science, Technology and Innovation for the funding of the CELCORR project.

\section{REFERENCES}

[1] B. Noh and S. Jung, "Characteristics of environmental factor for electrochemical migration on printed circuit board," J. Mater. Sci., Mater Electron., vol. 19, no. 10, pp. 952-956, Oct. 2008.

[2] B. A. Smith and L. J. Turbini, "Characterizing the weak organic acids used in low solids fluxes," J. Electron. Mater., vol. 28, no. 11, pp. 1299-1306, Nov. 1999.

[3] R. Ambat and P. Møller, "Corrosion and environmental effects on electronics," in Proc. 'Korrosion-Mekanismer, Havarier, Beskyttelse', 2005, pp. 161-178. DMS Vintermødebog.

[4] T. Takemoto, R. M. Latanision, T. W. Eagar, and A. Matsunawa, "Electrochemical migration tests of solder alloys in pure water," Corros. Sci., vol. 39, no. 8, pp. 1430-1715, Aug. 1997.

[5] M. Pourbaix, Atlas of Electrochemical Equilibria in Aqueous Solutions. Houston, TX: NACE, 1974. Cebelcor.

[6] T. Kawanobe and K. Otsuka, "Metal migration in electronic components," in Proc. Electron. Compon. Conf., 1982, pp. 220-228.

[7] S. Nishigaki, J. Fukuta, S. Yano, H. Kawabe, K. Noda, and M. Fukaya, "New low temperature fireable Ag multilayer ceramic substrate having post-fired $\mathrm{Cu}$ conductor (LFC-2)," in Proc. Int. Soc. Hybrid Microelectron., 1986, pp. 429-449.

[8] S. J. Krumbein, "Tutorial: Electrolytic models for metallic electromigration failure mechanisms," IEEE Trans. Rel., vol. 44, no. 4, pp. 539-549, Dec. 1995.

[9] S. Brunauer, P. H. Emmett, and E. Teller, "Adsorption of gases in multimolecular layers," J. Amer. Chem. Soc., vol. 60, no. 2, pp. 309-319, Feb. 1938.

[10] D. E. Yost, "Silver migration in printed circuits," in Proc. Symp. Printed Circuits, Philadelphia, PA, 1955, pp. 53-56.

[11] G. T. Kohman, H. W. Hermance, and G. H. Downes, "Silver migration in electrical insulation,” Bell Syst. Tech. J., vol. 34, no. 6, pp. 1115-1147, 1955

[12] S. W. Chaikin, J. Janney, F. M. Church, and C. W. McClelland, "Silver migration and printed wiring," Ind. Eng. Chem., vol. 51, no. 3, pp. 299 304, Mar. 1959. 
[13] S. J. Krumbein and A. H. Reed, "New studies of silver electromigration," in Proc. 9th Int. Conf. Elect. Contact Phenom., 1978, p. 145.

[14] A. Der Marderosian and C. Murphy, "Humidity threshold variations for dendrite growth on hybrid surfaces," in Proc. Int. Rel. Phys. Symp., 1977, p. 92.

[15] G. DiGiacomo, "Metal migration $(\mathrm{Ag}, \mathrm{Cu}, \mathrm{Pb})$ in encapsulated modules and time-to-fail model as a function of the environment and package properties," in Proc. Int. Rel. Phys. Symp., 1982, pp. 27-33.

[16] L. J. Turbini, J. A. Jachim, G. B. Freeman, and J. F. Lane, "Characterizing water soluble fluxes: Surface insulation resistance versus electrochemical migration," in Proc. CHMT Int. Electron. Manuf. Technol. Symp., 1972, pp. 80-84.

[17] D. Shangguan, A. Achari, and W. Green, "Application of lead-free eutectic Sn-Ag solder in no-clean thick film electronic modules," IEEE Trans. Compon., Packag., Manuf. Technol. B, vol. 17, no. 4, pp. 603-611, Nov. 1994

[18] M. Zamonzadeh, S. L. Moilink, G. W. Warren, P. Wynblatt, and B. Yan, "Electrochemical examination of dendritic growth on electronic devices in HC1 electrolytes," Corrosion, vol. 46, pp. 665-671, 1990.

[19] C. W. Jennings, "Filament formation on printed wiring boards," IPC Tech. Rev., pp. 9-16, 1976.

[20] A. Shumka and R. R. Piety, "Migrated-gold resistive shorts in microcircuits," in Proc. Int. Rel. Phys. Symp., 1975, pp. 93-98.

[21] F. G. Grunthaner, T. W. Griswold, and P. J. Clendening, "Migratory gold resistive shorts: chemical aspects of a failure mechanism," in Proc. Int. Rel. Phys. Symp., 1975, pp. 99-106.

[22] A. Shumka, "Analysis of migrated-gold resistive short failures in integrated circuits," in Proc. Tech. Program Int. Microelectron. Conf., 1976, p. 156.

[23] P. E. Rogren, "Electro migration in thick film conductor materials," in Proc. Tech. Program Int. Microelectron. Conf., 1976, p. 267.

[24] A. D. Marderosian and C. Murphy, "Humidity threshold variations for dendrite growth on hybrid substrates," in Proc. 15th Annu. Rel. Phys. Symp., 1977, pp. 92-100.

[25] N. L. Sbar, "Bias-humidity performance of encapsulated and unencapsulated Ti-Pd-Au thin-film conductors in an environment contaminated with Cl2," IEEE Trans. Parts, Hybrids, Packag., vol. PHP-12, no. 3, pp. 176-181, Sep. 1976.

[26] R. P. Frankenthal, "Corrosion failure mechanisms for gold metallizations in electronic circuits," J. Electrochem. Soc., vol. 126, no. 10, pp. 17181719, Oct. 1979

[27] B. Noh, J. Lee, and S. Jung, "Effect of surface finish material on printed circuit board for electrochemical migration," Microelectron. Reliab., vol. 48, no. 4, pp. 652-656, Apr. 2008.

[28] Y. R. Yoo and Y. S. Kim, "Influence of corrosion properties on electrochemical migration susceptibility of $\mathrm{SnPb}$ solders for PCBs," Met. Mater. Int., vol. 13, no. 3, pp. 129-137, 2007.

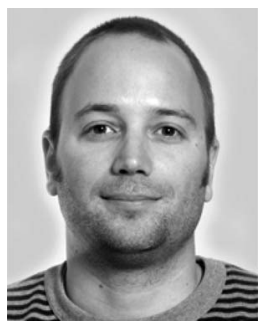

Daniel Minzari received the M.Sc. degree in materials science engineering with a background in applied physics from the Technical University of Denmark, Lyngby, Denmark. He is currently working toward the Ph.D. degree with the Department of Mechanical Engineering, Technical University of Denmark. His thesis is on "Corrosion Mechanisms in Electronics," with emphasis on establishing reliable test methods for the investigation of electrochemical migration on the component and device levels. His previous research has been focused on corrosion and on surface modifications using atmospheric plasmas.

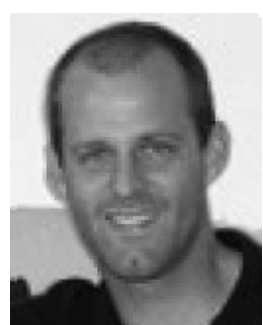

Morten S. Jellesen received the M.Sc. degree in chemical engineering and the Ph.D. degree from the Technical University of Denmark (DTU), Lyngby, Denmark.

$\mathrm{He}$ is currently with the Department of Mechanical Engineering, DTU. His postdoctoral research is primarily focused on corrosion in electronics.

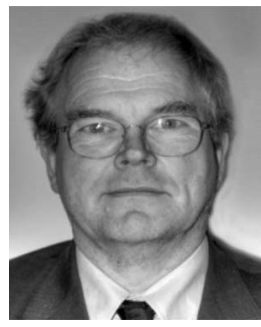

Per Møller is a Professor of corrosion and surface technology with the Department of Mechanical Engineering, Technical University of Denmark, Lyngby, Denmark. He is and has been head of several major national and international research projects and is a member of several company boards. He is also actively involved in innovative research groups connected to several major international companies. $\mathrm{He}$ is an author and coauthor of more than 130 scientific papers and several books on surface technology. $\mathrm{He}$ is the holder of more than 20 patents.

Prof. Møller is an appointed member of the European Academy of Surface Technology and a former member of The Research Board of the American Electroplaters and Surface Finishers Society.

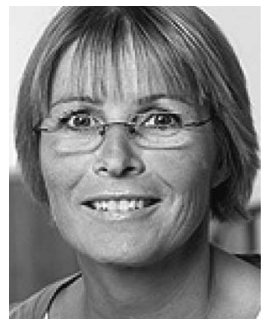

Pia Wahlberg has established a comprehensive and recognized scanning electron microscopy laboratory at the Technological Institute of Denmark, Tåstrup, Denmark. She is currently the Head of the Section for Electron Microscopy and Surface Analysis, Department for Micro Technology and Surface Analysis, Technological Institute of Denmark, with extensive network with companies and research institutions.

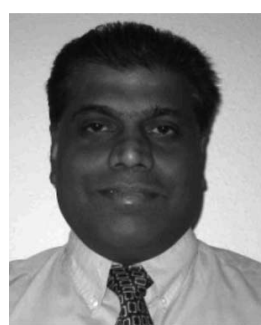

Rajan Ambat received the Ph.D. degree from the Indian Institute of Science, Bangalore, India.

He was an EPSRC Research Fellow with The University of Birmingham, Birmingham, U.K., and worked in collaboration with Airbus, BAE systems, Alcan International, and Jaguar. He is currently an Associate Professor with the Department of Mechanical Engineering, Technical University of Denmark, Lyngby, Denmark, and the Centre Manager for "Centre for Electronic Corrosion (CELCORR)." He is also a member of the Editorial Board of "Corrosion Engineering, Science, and Technology," which is a journal of The Institute of Materials, Minerals and Mining (IOM3, www.celcorr.com). He teaches courses on materials in advanced applications and products, including materials on printed circuit board (PCB) assembly, PCB manufacturing, and corrosion issues. His current research interests include corrosion reliability of electronic devices, materials for electronic contacts, high-resolution electrochemical measurements and test methods for electronic corrosion, intelligent nanocoatings on aluminum, and biomechanics.

Prof. Ambat is a member of the Electrochemical Society and The Minerals, Metals, and Materials Society. 